Supplement of

\title{
Radioactive waste management ethics and public policy: a precautionary approach
}

\section{Daniel Oross et al.}

Correspondence to: Eszter Matyas (matyas.eszter@tk.hu)

The copyright of individual parts of the supplement might differ from the article licence. 


\title{
Radioactive Waste Management Ethics and Public Policy: A Precautionary Approach
}

\author{
Dániel Oross, Centre for Social Sciences, Budapest \\ Miklós Zala, Centre for Social Sciences, Budapest
}

Eszter Mátyás, Centre for Social Sciences, Budapest, Central European University, Vienna, Austria 


\section{Introduction}

The focus of our presentation is on how to regulate risky technologies, old such as nuclear waste management and new (such as geoengineering). Thus, we aim to contribute to a better understanding of the ethical, political, and socio-economic aspects of radioactive waste management-related risks.

The Paks II project allows us to present how to set up procedures where some radioactive waste-related risks will not derail decision-makers and how they can be held accountable by the public.

The case of Paks II is also compelling as of today there is only nineteen countries in the world which are in the process of new reactor building (World Nuclear Association 2021). 


\section{Precautionary Principle(s) \\ "better safe than sorry"}

Different formulation of the PP aim to prevent harmful scenarios.

"This demand is partly motivated by the consequences of regulatory practices of the past. Often, chances of harm were disregarded because there was no scientific proof of a causal connection between an activity or substance and chances of harm, for example, between asbestos and lung diseases. When this connection was finally established, it was often too late to prevent severe damage" (Rechintzer 2020)

The precautionary approach is important to green political movements since the ' $80 \mathrm{~s}$; the idea appears in several official declarations, such as the Rio Declaration on Environment and Development (15th principle). 


\section{The necessary conditions of a PP}

Manson (2002): all PPs have three conditions:

- a "damage condition" (what kinds of bad outcomes are relevant?)

- a "knowledge condition" (what kind of epistemic conditions are required-are we dealing with uncertainty or probability?)

- a "remedy" (what should be the right response?)

Gardiner's (2006) three conditions of a PP:

- "threat of harm"

- "[u]ncertainty of impact and causality"

- "precautionary response" 


\section{Functions of different PPs: $3+1$ Rechnitzer (2020)}

Rechnitzer (2020): Functions of different PPS: „PP interpretations differ with respect to the function they are intended to fulfill"

„- Action-guiding principles tell us which course of action to choose given certain circumstances;

- (sets of) epistemic principles tell us what we should reasonably believe under conditions of uncertainty;

- procedural principles express requirements for decision-making, and tell us how we should choose a course of action" (Rechnitzer 2020)

\section{Plus: Integrated PPs}

„Integrated PP interpretations: Approaches that integrate action-guiding, epistemic, and procedural elements associated with PPs" (Rechnitzer 2020) 
PP as an important part of a broader approach to environmental preservation and sustainability (Ahteensuu 2008; Rechnitzer 2020)

Rechnitzer (2020): Sustainability might be too broad an idea $\Rightarrow$ We either need to „operationalize the vague concept [of sustainability] into a principle for policymaking, along with other principles, like the „polluter pays principle" [which holds chief emitting countries responsible for past emissions]"

...or to point out that "harm to the environment can affect many other moral concerns, for example, human rights and both international and intergenerational justice" (Rechnitzer 2020) 


\section{Justifying PPs 2: Historical Arguments}

Correcting existing practices: In the past, not making precautionary decisions lead to considerable long-term harm to human health or the environment (Harremoës et al. 2001; Rechnitzer 2020)

Learning from past mistakes: „....precaution is a reaction to our partial knowledge of environmental processes. Precaution is the most general norm in a hierarchy of norms that aims to translate environmental learning into policy. If a general stance of precaution is justified, it is because twentieth-century experience has revealed previously unsuspected sources of environmental degradation. Avoiding these problems requires learning our lesson and adapting our social institutions" (Whiteside 2006, 114) 


\section{Radioactive Waste in Hungary}
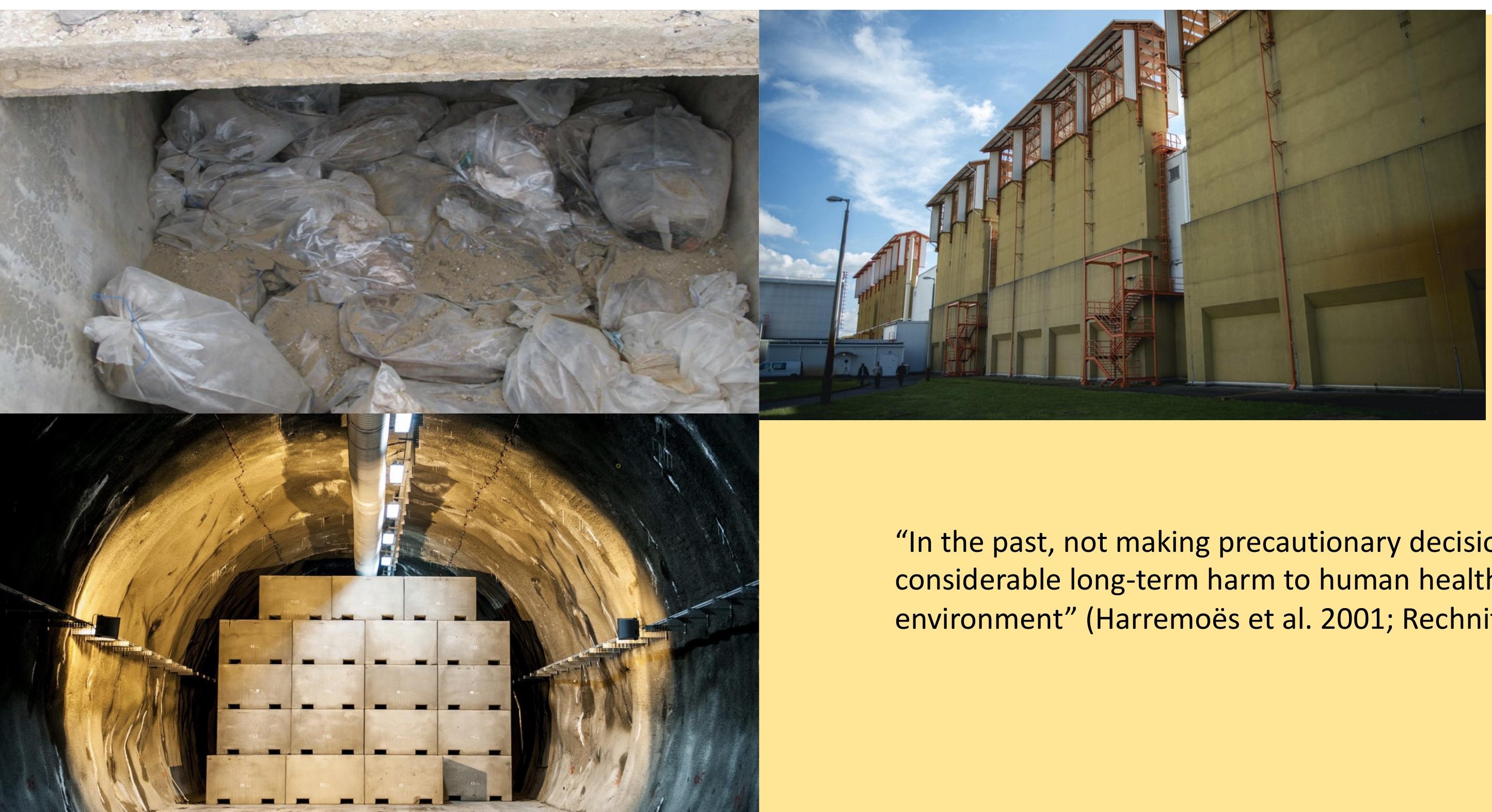

"In the past, not making precautionary decisions lead to considerable long-term harm to human health or the environment" (Harremoës et al. 2001; Rechnitzer 2020) 


\section{Concerns that arise}

i. Deep geological disposal in the Boda region

ii. Mayors of the potentially affected communities founded an association to organize their interests

iii. No transparency

iv. No dialogue

v. Cost and financing

i. 1998, Central Nuclear Financial Fund

ii. Polluter-pays-principle

iii. How about the future costs? 


\section{Special Cases}

\section{Püspökszilágy}

- tritium and radiocarbon leaks

- lack of background radiation meter

- security enhancement program

\section{Boda}

- conflicting interests

- public resistance

- on the national political agenda

In summary: radioactive waste management is still in its infancy. Might not be able to realize the plans by the time Paks II is built. Not at all certain yet if the best possible safety can be ensured Central Nuclear Financial Fund Waste quantities will rise substantially. The need for a final repository is urgent. 
The problem of "regulatory drift": regulatory complacency + regulatory gifting + thin market capture

1. Starting point: the "risk triangle." => Three roles: decision-maker; the one who benefits if things go well; the one who suffers if things go wrong (Hermansson and Hansson 2007)

Moral hazard: the person who makes the decision enjoys its benefits if things go well, but another one suffers if things go badly. Will the agent be cautious if the possible harms do not fall on him?

2. Consequent problems Wolff $(2019,11)$ : a) „regulatory complacency": regulators approve a new technology and for a while, no problems occur. $=>$ 


\section{Regulatory Gifting and „Thin Market” Capture}

$\Rightarrow$ Then technology develops over time calling for further approvals but if nothing goes wrong, regulatory resources are channeled away.

b) „regulatory gifting”: things are still going well and deregulation happens, where the "government allows industry to self-regulate, perhaps as part of an electoral promise to 'cut red tape', and often on the agreement that other benefits will be provided in return, yet these benefits may never in fact materialise" (Wolff 2019, 11).

c) "thin market" capture by those who are in favor of a new technology. I.e. after the initial regulators moved on for other tasks, others will be needed to fill regulatory panels, and "those who have some history in the industry may be the only plausible candidates" (Wolff 2019, 11). 
$=>$ "it is very likely that regulators recruited from industry wilf show a degree of sympathy for [the new technology industry concerns], whether or not they still have any official role there. In other words, thin markets will have a tendency to lead to regulatory capture, accidental or otherwise" (Wolff 2019, 12).

3. A further problem: the costs of weak (but also strong) regulation might lead to an outcome where worst-off groups disproportionately share most of the burdens and costs of a new technology (Wolff 2019, 17).

$\Rightarrow$ To avoid these negative outcomes, there must be a regulatory principle (that does not allow the worst-off to suffer disproportional burdens); the role of civil society groups in monitoring a given technology is indispensable.

$\Rightarrow$ Consider animal rights activists' achievements. 
The practices of the emerging era of public engagement tap into the current debates on democratic politics in political theory with the emergence of deliberative democracy (Bohman and Rehg 1997; Dryzek 2000; Gutmann and Thompson 2009), and radical democracy (Laclau and Mouffe 2001; Mouffe 2000, 1999).

A fieldwork complemented by the existing but limited literature on the planning reform (Fabók 2016) explored how the formal public consultations are rescaled, how politics is displaced from planning inquiries to legal wrangles and 'boundary works':

- "Rescaling" the planning process across geographic scales, such as national and local levels can be an instrument of manufacturing consent.

- The planning process is fragmented into a series of separate issues, the megainvestment project is broken up into disjointed issues by drawing geographic boundaries, and by segregating nuclear (e.g., GDA) and non-nuclear components, together with technical and generic concerns. This causes 'consultation fatigue' among citizens. 


\section{Thank you for your attention!}

- As we our in the preparatory phase of our project, please let us know how you like the idea and/or if you'd like to join our project

- HORIZON-CL5-2022-D1-01-02-twostage: Socio-economic risks of climate change in Europe

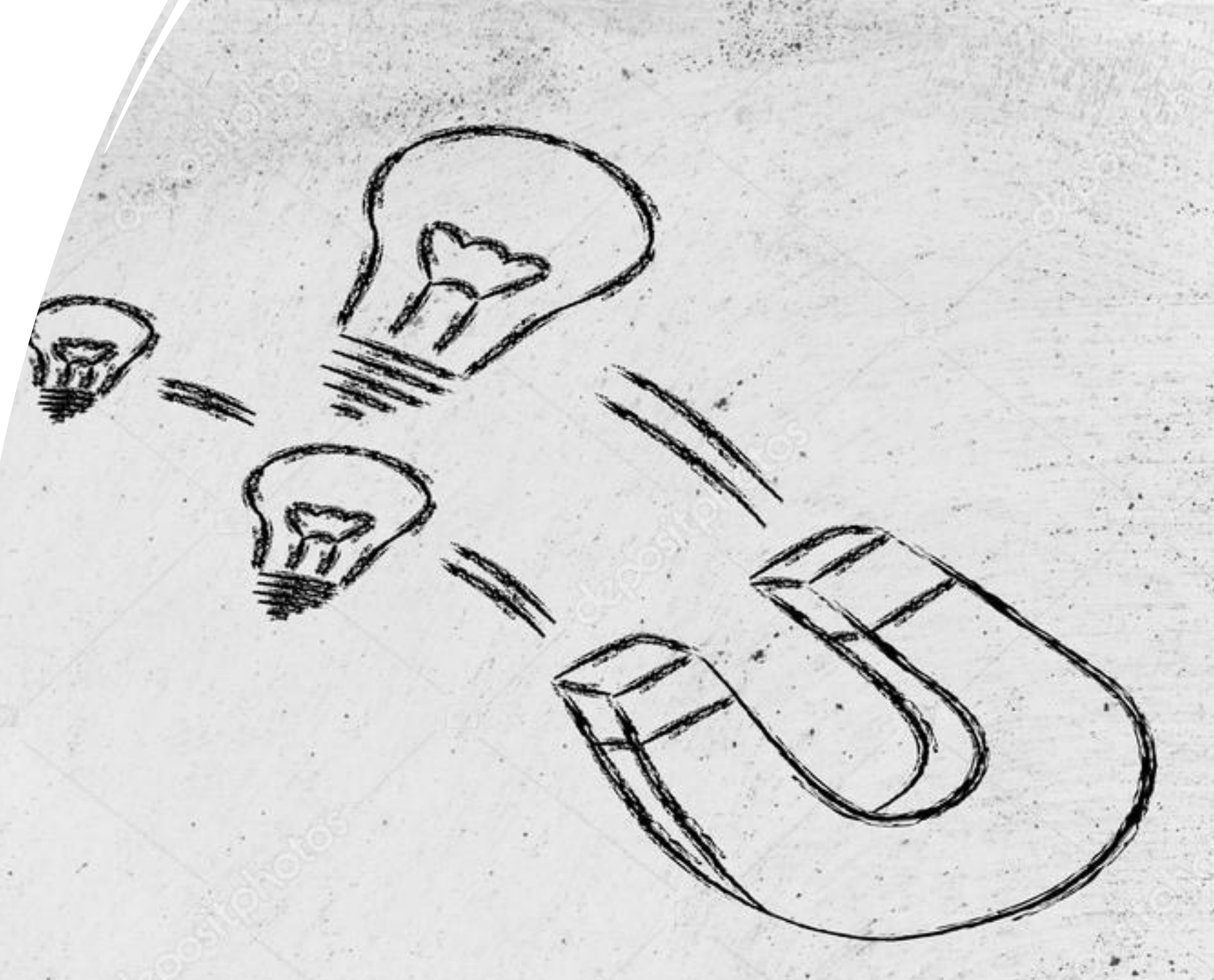




\section{References}

Ahteensuu, Marko. 2008. „In Dubio Pro Natura? A Philosophical Analysis of the Precautionary Principle in Environmental and Health Risk Governance." PhD thesis, Turku, Finland: University of Turku.

Fabók, Márton (2016):Governing a nuclear megainvestment: A multi-scalar ethnography of Wylfa Newydd https://livrepository.liverpool.ac.uk/3007544/1/200921556_Sep2016.pdf

Gardiner, Stephen M. 2006. „A Core Precautionary Principle”, Journal of Political Philosophy, 14(1): 33-60.

Harremoës, Poul, David Gee, Malcolm MacGarvin, Andy Stirling, Jane Keys, Brian Wynne, and Sofia Guedes Vaz. 2001. Late Lessons from Early Warnings: The Precautionary Principle 1896-2000. Office for Official Publications of the European Communities.

Hermansson, Hélène, and Hansson, Sven Ove. 2007. „A three-party model tool for ethical risk analysis,” Risk Management, 9(3), 129-144.

Manson, Neil A. 2002. „Formulating the Precautionary Principle”, Environmental Ethics, 24(3): $263-274$.

Rechnitzer, Tanja. 2020. „Precautionary Principles,” Internet Encyclopedia of Philosophy, available at https://iep.utm.edu/pre-caut/

Whiteside, Kerry H. 2006. Precautionary Politics: Principle and Practice in Confronting Environmental Risk. MIT Press Cambridge, MA.

Wolff, Jonathan. 2019. „Fighting risk with risk: solar radiation management, regulatory drift, and minimal justice,”

Critical Review of International Social and Political Philosophy, Published online: 20 Nov 2019: 1-20. 